\title{
Proceeding
}

Supplementary Issue: Spring Conferences of Sports Science. Costa Blanca Sports Science Events, 19-20 June 2020. Alicante, Spain.

\section{Balance analysis in adolescents based on a motion capture platform}

\author{
MAURO CALLEJAS-CUERVO ${ }^{1}$, JOSÉ LUIS JAIME-GIL², LUIS ARTURO MONROY-GUERRERO² \\ ${ }^{1}$ School of Computer Science, Software Research Group, Pedagogical and Technological University of \\ Colombia, Colombia \\ ${ }^{2}$ School of Physical Education and Recreation and Sports, Pedagogical Trends Group, Pedagogical and \\ Technological University of Colombia, Colombia
}

\begin{abstract}
An assessment of the level of balance in adolescents was done, using motion capture technologies (IMOCAP). The sample was 7 peoples, to whom a pre-test and then a post-test and intervention program were applied. The duration of the intervention program was 11 weeks, with a weekly basic gymnastics' session of 120 minutes. A diagnosis of anthropometric factors was carried out on characteristics such as size, with an average of $1.62 \mathrm{~cm}$. (SD =0.059), weight, with an average of $54.12 \mathrm{~kg}$. (SD = 6.89) and age, with an average of 15 years with $S D=1.11$. Consecutively, a pre-test for static balance was applied, using IMOCAP. An intervention program was designed, with the aim of improving corporal stability. Afterwards, the post-test was applied using IMOCAP. There was an improvement in the execution of basic gymnastic movements and greater stability was perceived. This was confirmed by the results registered by the instructor and the measurements generated by IMOCAP, which indicated a lesser degree of inclination and rotation of the torso in the post-test $\left(+/-7.35^{\circ}\right.$ and $3.7^{\circ}$ on average) for the three body axes. Most of the basic gymnastic movements help to improve body stability, corroborated by a high-precision, reliable platform with quantifiable result-delivery.
\end{abstract}

Keywords: Balance; Inertial and magnetic sensors; Biomechanical; Intervention program; Gymnastics.

\section{Cite this article as:}

Callejas-Cuervo, M., Jaime-Gil, J.L., \& Monroy-Guerrero, L.A. (2020). Balance analysis in adolescents based on a motion capture platform. Journal of Human Sport and Exercise, 15(3proc), S723-S734. doi:https://doi.org/10.14198/jhse.2020.15.Proc3.23

\footnotetext{
Corresponding author. School of Computer Science, Software Research Group, Pedagogical and Technological University of Colombia, Avenida Central del Norte 39-115, 150002, Tunja, Boyacá, Colombia. https://orcid.org/0000-0001-9894-8737 E-mail: mauro.callejas@uptc.edu.co

Supplementary Issue: Spring Conferences of Sports Science. Costa Blanca Sports Science Events, 19-20 June 2020. Alicante, Spain.

JOURNAL OF HUMAN SPORT \& EXERCISE ISSN 1988-5202

(c) Faculty of Education. University of Alicante

doi:10.14198/jhse.2020.15.Proc3.23
} 


\section{INTRODUCTION}

Currently, technology plays a fundamental part in most areas of study and it has been an invaluable support in health, sport and education. A number of studies have been carried out using accelerometers in order to supervise the practice of physical activity, promoting habits and healthy lifestyles in people of an advanced age (Leirós Rodríguez, Arce, García Soidán, \& Barbeito, 2017). This technology is not only limited to its applicability for senior citizens; studies to measure the level of physical activity in primary education students have also been found (Martínez Martínez, Contreras Jordán, Aznar Laín, \& Lera Navarro, 2012), being able to show in quantifiable values the levels of physical activity among a population of children and young people. Likewise, these sensors have helped to capture body movement in patients at risk of falling based on data from accelerometry (Miralles et al, 2012), showing that in the last decade its application has become widespread, being suitable for application in the fields of health, movement and human motion. Thus, different ways of evaluating and optimizing the processes that lead to improvements in the quality of life of human beings have emerged.

Specifically, in the case of technologies that support the taking of measurements regarding balance, several studies have been found which confirm new evaluation systems for balance in adult women, with kinematic elements (Leirós Rodríguez, Arce Fariña, \& García, 2015a), carrying out tests using different positions and evaluation conditions. The results obtained were contrasted with clinical tests, such as the TUG, presenting a high correlation in unipedal position without visual reference. This shows that its pertinence and objectivity have led to new investigations that integrate evaluation models that contribute to recording precise and reliable data regarding body balance. The application of this technology is recognized for all ages. In this context, there are research projects that have evaluated postural balance while standing and sitting in healthy individuals through accelerometry (Caña Pino, Apolo Arenas, Moral Blanco, Álvaro de Diego, \& Fernández Gutiérrez, 2015), allowing for the recording of body accelerations in different conditions.

At present, the most common way of carrying out this type of assessment is through clinical tests, as used in the area of health, or physical tests, used in the area of physical education, through direct observation; though with some subjective measures that, on certain occasions, may not be as reliable, depending on the perspective of the researcher.

Due to the above, this investigation was conducted in order to continue contributing with new diagnostic systems and balance evaluations. In this case, the sample was a group of students and a platform for the analysis of body variations in different conditions was implemented, which integrated different motion sensors. In addition, this research used observational records made during the intervention process as support. The study was developed by following a new methodological perspective "that has become stronger in the last decade according to the current need of more comprehensive approaches when it comes to human motion" (Castañer Balcells, Camerino Foguet, \& Anguera Argilaga, 2013), using quantitative instruments, making use of emerging motion capture technologies and observation records; all this, in order to integrate a more accurate research that contributes to fostering advancements in the analysis of body control.

The analysis of the Static Balance Test implementing the motion capture system platform performs a process denominated data fusion, which is determinant when integrating the data captured by the three sensors that make up the platform: an accelerometer, gyroscope and magnetometer, so as to obtain the proper quality and integrity of the data required. In this case, the degrees of movement in the three body axes are evaluated throughout the four tests of static balance, for the pre- as well as for the post- test, of each one of the individuals assessed. 
This process has multiple advantages, given that it helps to maintain the reliability of the data, which is finally expressed in degrees. Data fusion uses the redundant data of the sensors to reduce the uncertainty in the results obtained. In addition, it allows for an increase in the precision of the data recorded due to the integration of the information; this increases reliability in case of sensor errors or failure. The supplementary data of the sensors used permits the characterization of the environment perceived in a way that would be impossible using the sensors separately.

\section{Related Works}

This section presents some of the works related to the analysis of balance with the use of emerging technologies which permits the quantification of the measurement of a person's stability levels. Forechi, et al, (2018) carried out a study on elderly people who suffered from Post-Chikungunya Chronic arthralgia (PCCA). Their levels of balance, gait, pain and plantar pressure were analysed, for which accelerometers and gyroscopes were utilized. The results showed that the patients with PCCA had difficulties walking, and less synchronization and stride length, resulting in an alteration in their gait and its phases. In another study, Patel, Pavic, \& Goodwi (2020) conducted a review of the literature, the objective of which was to identify the measurements and variables of the stride and posture of senior citizens, with the aid of inertial sensors. In this study, the authors analysed articles from various databases, resulting in a total of 35 documents which deal with measurements obtained with sensors and that said measurements are correlated with traditional clinical balance tests. Moreover, the authors showed that the use of one inertial sensor placed on the posterior inferior part of the torso is the most effective location for determining the multiple risk factors of falling.

The use of this technology is applicable to pathologies that affect and alter the gait and balance of human beings, some of these being preliminary characteristics of diseases that affect motricity. In their study, Morrisa et al (2019) suggested a set of characteristics of gait and balance, which are related to cognition in Parkinson's disease (PD). The authors developed gait and balance models, identifying which characteristics relate better with cognition in the gait and balance phases. The results of the study indicated independent associations in a gait model and a balance model. Furthermore, a study that took place in the University of Taiwan, by Chia-Hsuan Lee \& Tien-Lung Sun (2018), presents an evaluation of balance with force plates and inertial sensors. In the realization of the test, the individuals start in a bipedal position on a force plate and use an inertial sensor while trying to maintain stability for 30 seconds, in 4 random trials. The researchers used a Wilcox test to confirm if the conditions were significant. The results showed that the measurements of the sensor were preferred for the motion analysis of the lower limbs. The conclusion of the authors is that both of the tools used appear to be suitable for the evaluation of balance; in addition, they can be easily adapted to different needs.

At present, there are different methods for the evaluation of balance, in clinical practice as well as in sport practice. However, they tend to be subjective, and their reliability and sensitivity can be limited. For this reason, the use of inertial and magnetic sensors has increased in the last decade, increasing their scientific validity. In the study presented by Noamani, Nazarahari, Lewicke, Vettea, \& Rouhani (2020), the authors make a comparison between inertial measurement units (IMU) and a force platform to characterize balance in a bipedal position. The tests for said comparison consisted of 10 subjects who do not suffer from any disability adopting a bipedal position for 2 minutes. The authors employed different approaches to estimating inter-segmental moments and centre of pressure (COP). According to the results, the orientation of the segments, ground reaction forces and the position of the centre of pressure could be estimated. 
The research work we are presenting is different from the abovementioned works in several aspects, among them can be highlighted the measurement of the anteroposterior, mediolateral and craniocaudal axes, with a motion capture platform developed by our research group. This platform uses the measurement of accelerometers, gyroscopes and magnetometers, which allow an analysis to be carried out in 9 degrees of freedom and an understanding of the movements involved in inclination, declination and body rotation. Additionally, a training program was implemented, based on movements of school gymnastics and postural re-education in physical education classes in order to improve balance. In order to register the progress of the subjects assessed, a pre-test was carried out, which afterwards was compared with the results obtained in the post-test. Also, an analysis of the implementation of a gymnastics program and the validity of the use of the platform in measuring balance was conducted.

\section{MATERIALS AND METHODS}

The motion capture platform was implemented according to the protocol established by the study: Identification of anatomical reference points for the evaluation of balance through kinematic devices, (Leirós Rodríguez R, Arce, Souto Gestal, \& García Soidán, 2015b), identifying that, according to the results, "the point where to place the device is in the lumbar-pelvic region, over the sacral base, which permits that the fourth lumbar level is considered as the most suitable kinematic record point".

For the localization of the fourth lumbar vertebra (L4) and later placement of the device, the protocol of the Atlas of Palpatory Anatomy (Tixa, 2006, p. 41), was used. Once the spinous process is located, the next step is to attach the Fixomull transparent, hypoallergenic tape on the process, together with the super strong, double-sided tape and the motion sensors to ensure that it does not move independently of the torso of the individual during the tests.

Once the sensors are placed, the test was selected to measure static balance. This test has had a high degree of scientific validity in previous studies, which has 2 conditions and positions of evaluation. (Leirós Rodríguez \& others, 2015a).

Before the test, anthropometric measurements were taken for size, mass, age and gender, in the corresponding unit, with the aim of determining the greatest homogeneity possible, necessary in these studies, by means of controlling for possible alien variables or "factors that affect balance" (Contreras Rodríguez, 2011). The inclusion criteria that were taken into consideration in Pilot study for the measurement of balance with a kinematic element in adult women were: the inability to walk independently, without the use of external orthopaedic elements; to maintain bipedal static balance with eyes open for 60 seconds; to have some counter indication or illness that was an impediment for the person to take some of the tests; not to be able to participate in one or more of the sessions of the intervention; all the above, with the objective of not skewing the diagnostic records as well as the final tests.

In accordance with the inclusion criteria, the group was formed of 7 students, 6 boys and 1 girl.

\section{Test development}

Each individual evaluated had to be barefoot but wearing socks and comfortable clothes to carry out the tests at ease, without any type of inhibition when performing movements of rebalancing. The initial reference position for the test was marked on the floor, so the longitudinal axis should coincide with the intersection of the lines marked, vertical and horizontal, without changing natural bipedal posture. During the four tests, the individual should be as still as possible, trying to maintain an upright position. In the unipedal balance tests, 
the individual was able to choose which leg to use as support, so all of them could practice before starting the test, a visualization of this positions are presented in Table 1.

Table 1. Test evaluation positions.

Type of test
I. Bipedal balance test with eyes open. (EBOA, by its acronym
in Spanish).
II. Bipedal balance test with eyes closed. (EBOC, by its acronym
in Spanish).
III. Unipedal balance test with eyes open. (EMOA, by its
acronym in Spanish).
IV. Unipedal balance test with eyes closed. (EMOC, by its
acronym in Spanish).

Once the pre-test had taken place, the intervention program on basic gymnastics was implemented, which constituted of approximately twelve sessions of two hours per week, including those when the pre-test and post-test were applied.

After the intervention, the group was evaluated through a post-test in order to verify the level of improvement in the movement records over 30 seconds for the 3 body axes. Particularly, this proposal intends to involve and support the perspective mentioned in the investigations cited, which claim that more systems are emerging, using motion capture technologies which are sensitive to the least disturbance4. This brings numerous advantages such as being independent of external references, lighting or friction, apart from the fact that the motion detected by these inertial sensors is directly related to the object. For (Abyarjoo, Barreto, Cofino, \& Ortega, 2014), "the inertial sensors are the autonomous technology that does not need external devices, such as cameras or transmitters used in submarines, spaceships and planes for many years." These microelectromechanical systems (MEMS), based on inertial sensors, have been more widely used in the last few decades given their size, low energy consumption, light and weight.

\section{Motion Capture platform (IMOCAP)}

The motion capture platform, represented in figure 1, which uses technology based on inertial and magnetic sensors, was implemented as it has a high degree of scientific validity in various research projects and scientific publications (Pacanchique, 2017; Pineda, 2016; Callejas-Cuervo, Gutierrez \& Hernandez, 2017; Callejas-Cuervo, Ruíz-Olaya, \& Gutiérrez, R.M. 2016; Callejas-Cuervo, Alvarez \& Alvarez, 2016). 


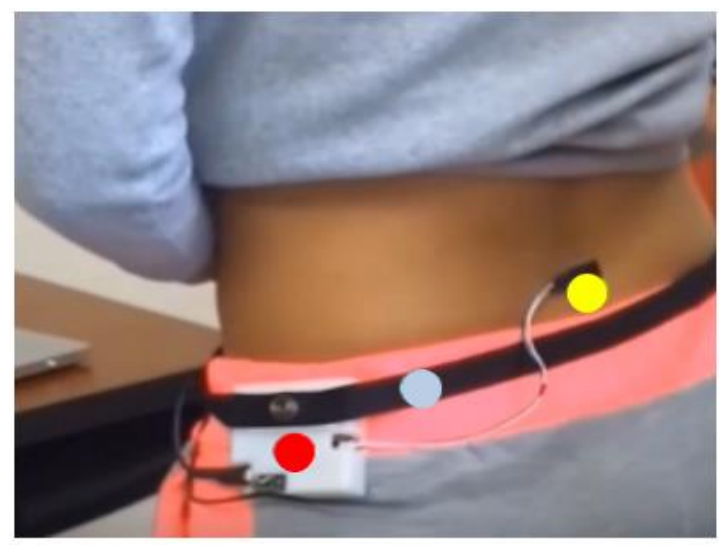

\section{IMOCAP Platform}

Motion Processing Unit

Adjustable Velcro belt

Figure 1. Motion capture system - IMOCAP.

This platform seeks to measure, from where the sensors are placed, "the spinous process L4", the peak degrees of movement and to identify the postural variations in ranges, expressed in degrees, for the 3 body axes: axis $Y$ corresponds to the anteroposterior axis, axis $X$ corresponds to the medial-lateral axis and axis $Z$ corresponds to the longitudinal or vertical axis. The lightness of the device and the easy data storage in a micro SD card together with its remote activation give it a lot of potential to be implemented at a clinical level.

\section{Participant observation recorded in the logs}

Participant observation is a technique implemented in research. "It is among the most outstanding due to its value in the investigation of verbal, didactic and mathematic language". (Medina, De La Herrán, \& Domínguez, 2014).

\section{RESULTS}

Table 2. Statistical description of the factors.

\begin{tabular}{|c|c|c|c|c|c|}
\hline \multirow{2}{*}{\multicolumn{2}{|c|}{$N$}} & Gender & Size & Weight in kg. & Age \\
\hline & & 7 & 7 & 7 & 7 \\
\hline \multicolumn{2}{|l|}{ Mean } & 1.14 & 16.214 & 541.286 & 15.71 \\
\hline \multicolumn{2}{|l|}{ Median } & 1.00 & 16.500 & 582.000 & 16.00 \\
\hline \multicolumn{2}{|l|}{ Mode } & 1 & 1,65 & $44.30^{\mathrm{a}}$ & $15^{\mathrm{a}}$ \\
\hline \multicolumn{2}{|l|}{ Standard deviation } & .378 & .05956 & 689.389 & 1.113 \\
\hline \multicolumn{2}{|l|}{ Asymmetry } & 2.646 & -.775 & -.558 & -.249 \\
\hline \multicolumn{2}{|l|}{ Asymmetry standard error } & .794 & .794 & .794 & .794 \\
\hline \multicolumn{2}{|l|}{ Kurtosis } & 7.000 & -.893 & -1.931 & -.944 \\
\hline \multicolumn{2}{|l|}{ Kurtosis standard error } & 1.587 & 1.587 & 1.587 & 1.587 \\
\hline \multicolumn{2}{|l|}{ Range } & 1 & .16 & 16.50 & 3 \\
\hline \multicolumn{2}{|l|}{ Minimum } & 1 & 1.53 & 44.30 & 14 \\
\hline \multicolumn{2}{|l|}{ Maximum } & 2 & 1.69 & 60.80 & 17 \\
\hline & 25 & 1.00 & 15.500 & 465.000 & 15.00 \\
\hline \multirow[t]{2}{*}{ Percentiles } & 50 & 1.00 & 16.500 & 582.000 & 16.00 \\
\hline & 75 & 1.00 & 16.600 & 600.000 & 17.00 \\
\hline
\end{tabular}

Note: a. There are multiple modes. Only the smallest value is shown. 
Starting from the previously mentioned processes, for the quantitative analysis, the information of factors taken into consideration is the following: gender, size, weight and age, in order to identify the homogeneity of the group analysed. The software used for the descriptive analysis of these factors was SPSS.

Table 2 shows the values of the group studied in relation to gender, age, size and weight in kilograms. It is possible to identify that $95 \%$ of the values are within a distance not greater than two standard deviations with respect to the mean, which proves that it is within the normal distribution.

Using the software MATLAB, a mathematical tool that offers an environment of integrated development with a programming language of its own, the graphs are represented in the signs captured by the three sensors, allowing for the identification of the peak accelerations and the rotational movement of the three body axes. Through data fusion, the measurements and data can be combined to give more complete and comprehensive information. It makes synergic use of the information coming from different sensors in order to achieve the right quality and integrity, allowing for the identification of maximum and minimum degrees of movement for 30 seconds in the 3 body axes, for each of the balance tests in each individual. By means of example, the information of participant №2 was randomly chosen, where the procedure used is represented.
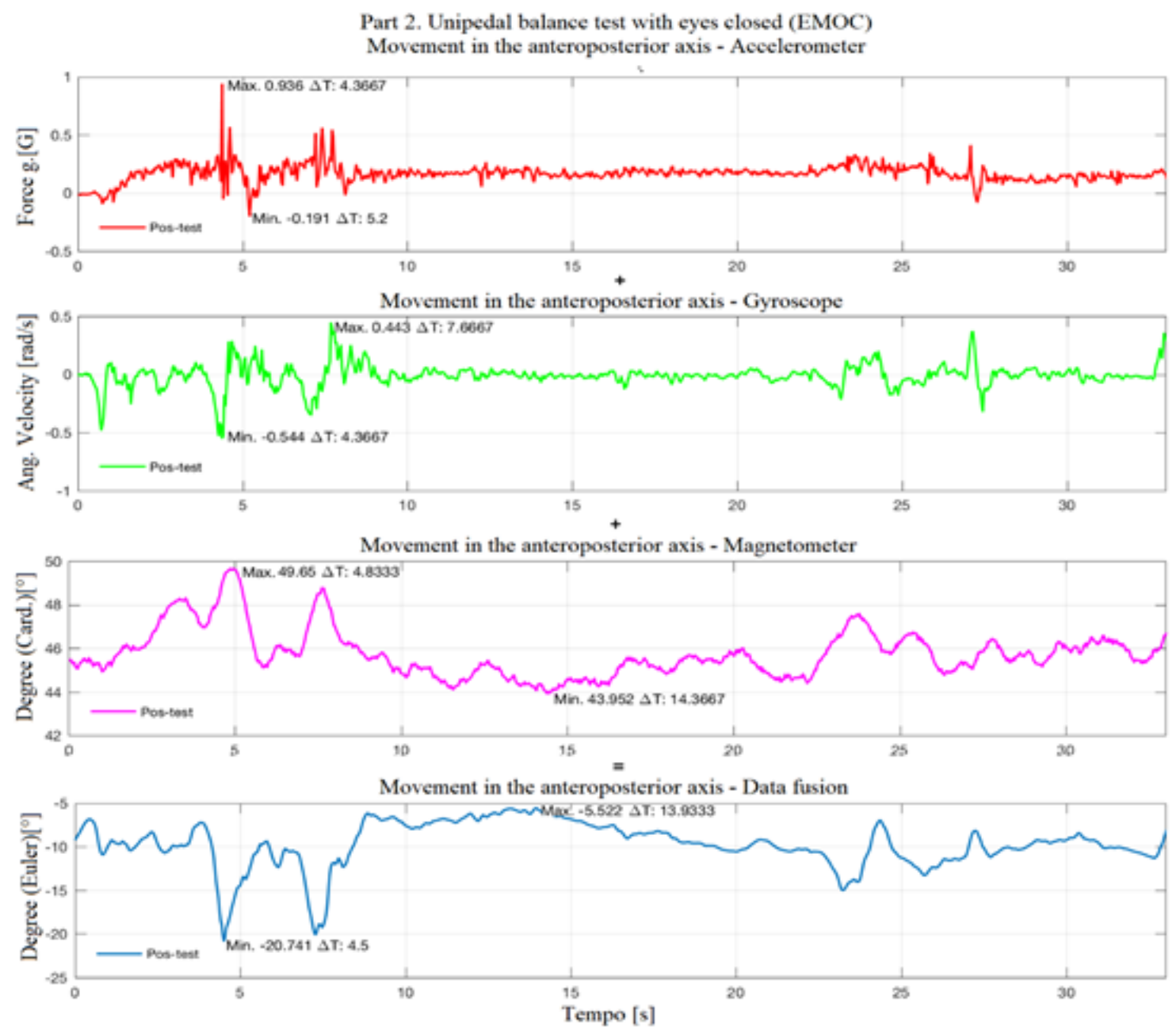

Figure 2. Representation of the peak signs. accelerometer, magnetometer, gyroscope and data fusion. 
Figure 2 represents the peak signals of the three sensors and the data fusion for test 4 (post-test): Unipedal balance test with eyes closed (EMOC, by its acronym in Spanish) - participant No2. The horizontal axis in the graph represents the seconds that each test lasts. These sensors take 30 samples per second. The red signal represents the data shown by the accelerometer, part $A$ in the graph. The green signal represents the data of the gyroscope, part B in the graph. The magenta signal represents the data of the magnetometer, part $C$ in the graph. Through data fusion, the blue signal is generated, part $D$ in the graph. This signal represents the peak degrees, maximum and minimum, of movement in the anteroposterior axis. This process had multiple advantages as it helped to obtain reliable data that would finally be expressed in degrees.

Once the information of the maximum and minimum peak degrees was obtained, the next step was to identify the ranges of movement that each student had in the pre-test and the post-test; this analysis was carried out in the Excel software, student version.

Starting from the movement peaks, calculations were made to find the total movement of the three axes and the difference in degrees of movement between the pre-test and the post-test in each body axis; anteroposterior, medial-lateral and craniocaudal or longitudinal axis, for each student.

Table 3. Average and total movement per axis - difference and percentage of improvement.

\begin{tabular}{|l|c|c|c|c|}
\hline \multirow{5}{*}{ The whole group studied Craniocaudal plane only } & Pre-Test & Post-Test & Difference & $\begin{array}{c}\text { Variation } \\
\text { Difference \% }\end{array}$ \\
\cline { 2 - 5 } & All Prb. & All Prb. & & \\
\cline { 2 - 5 } & $\Delta \mathrm{G}$ & $\Delta \mathrm{G}$ & & \\
\cline { 2 - 5 } & 10.94 & 5.42 & 5.53 & $50.51 \%$ \\
\cline { 2 - 5 } & 10.52 & 4.98 & 5.54 & $52.66 \%$ \\
\cline { 2 - 5 } & 8.47 & 4.77 & 3.70 & $43.70 \%$ \\
\hline & 13.84 & 6.50 & 7.35 & $53.06 \%$ \\
\hline
\end{tabular}

Table 3 presents the averages, in degrees of movement, of the group studied, in the pre-test and the posttest, as well as the difference and their respective percentage of improvement. The anteroposterior axis obtained a positive $5.54^{\circ}$ difference between the pre-test and the post-test. This result affirms that, during the four tests, on average, there was a reduction of the movement ranges. At the same time, the difference obtained by the medial-lateral axis was $3.70^{\circ}$ while the difference between the pre-test and the post-test in the craniocaudal axis was $7.35^{\circ}$.

For its part, the result of the average of the total movement of all the axes in the pre-test is $10.94^{\circ}$. The result obtained in the post-test is $5.42^{\circ}$ of movement, with a difference of $5.53^{\circ}$ between the pre-test and the posttest. On average, the group managed to control unbalancing movements, reaching greater stillness and, thus, improving their stability.

Finally, the total difference of movement generated in each axis was divided by the total result of the pretest, in order to calculate the percentage of improvement. The results obtained are: for the craniocaudal axis $53.06 \%$, for the anteroposterior axis $52.66 \%$ and for the medial-lateral $43.70 \%$. Once the result and the difference for each axis were found, the percentage of total improvement was calculated by dividing the total difference of movement by the total result of movement in the pre-test, obtaining the percentage of improvement of the group analysed, $50.51 \%$. 


\section{DISCUSSION}

Although all the results of the four tests evidence a reduction of movement, on average, for the three body axes, the richest and most relevant results took place in the last two tests, where ranges of less amplitude and oscillations were obtained. Despite these results for tests I (EBOA) and III (EMOA), there was an improvement of $3.8^{\circ}$ average, in agreement with the study by (Guimaraes, Hernández, Rodríguez \& García, 2015). The authors affirm that "there is evidence that supports the hypothesis that the practice and systematic repetition of specific balance exercises, in the different phases of a person's development, can lead to obtaining more sensitivity in your sensory receptors or a better integration of information provided by the structures responsible of regulating postural control" (p. 55-56).

With reference to the above, not only are the results positive in the aspect of static balance, both, unipedal and bipedal with eyes open, but also in tests II (EBOC) and IV (EMOC) where there was a noticeable decrease in movement, these two being the tests that stood out in the group studied, obtaining an average of $7.2^{\circ}$. This result coincides with the observations in the study by (Guimaraes Ribeiro, Hernández Suárez, Rodríguez Ruiz, \& García Manso, 2015, p. 56). The authors argue that "there are several investigations that have shown that different specialists (ballerinas and gymnasts) are significantly more stable and less dependent on their sight than untrained individuals". In this way, the intervention in gymnastics proves to be pertinent, having a positive response regarding balance without visual references.

Taking this into consideration, the records obtained in this study for the anteroposterior axis show that it was the second body axis that presented an improvement higher that $50 \%$. This results suggests the efficiency of the program regarding the stability of this body axis, which agrees with the study by (Guimaraes Ribeiro, Hernández Suárez, Rodríguez Ruiz, \& García Manso, 2015, p. 58), where it was found that "for the anteroposterior axis there are significant differences among groups: the gymnastics group showed lower values of spectral energy in both conditions, open eyes and closed eyes". According to (Guimaraes Ribeiro, Hernández Suárez, Rodríguez Ruiz, \& García Manso, 2015, p. 59), this "possibly has to do with the fact that children mature the postural control plain before the medial-lateral plain", which means that probably, in the range between 14 and 17 the movement control of this axis to maintain balance is still developing and that this is the right phase to stimulate it.

Furthermore, the ranges of movement obtained in the medial-lateral axis, for both the pre-test and the posttest, were lower than the movement in the anteroposterior and vertical axes, thus, postulating this axis as the most stable of the three. Contrasting the results of this study with those obtained by (Leirós Rodríguez, Arce Fariña, \& García Soidán, 2015a), in their study with adult women from 53 to 66 years of age, they do not match for "higher kinematic values were obtained in the medial-lateral plain, different from the other two." This result allows the argument that as the years pass, it is possible that the medial-lateral axis is more prone to imbalance, this means that a person loses their stability more easily.

Likewise, the results obtained in the study by (Caña Pino et al, 2015). "indicate that the oscillations of greater amplitude in the individuals to maintain balance are related to the coordinates X (vertical) and (medial-lateral). The data collected in this study showed that the anteroposterior axis or $Z$ axis presented variations of lower amplitude" in ages that range from 18 to 27 years of age. On the one hand, this contrasts with the results obtained in this research, where there is great similarity in the oscillations for the $Z$ axis, which was identified to have a greater amplitude of movement and an improvement in the anteroposterior and medial-lateral axes. On the other hand, the results differ in the medial-lateral axis as they indicate that this axis was the one to obtain the smallest oscillation and improvement. 
As per the records of data fusion for tests III and IV, it was determined that during the 30 seconds there are two critical points of imbalance. The first one is in the range of 0 to 10 seconds and the second one is between the range of 20 to 30 seconds. This information is in agreement with a study where greater records were obtained in the acceleration vector for these ranges in the unipedal balance test with open eyes and unipedal balance test with eyes closed. (Leirós Rodríguez, Arce Fariña, \& García Soidán, 2015a).

\section{CONCLUSIONS}

Through the use of IMOCAP and data fusion, it is possible to capture the movement generated in the different balance tests through the different sensors that form it, giving more objectivity to the records of the axes evaluated and identifying the degree of the dorso-lumbar movement generated by the rebalancing of the individuals. In this way, the kinematic evaluation is postulated as one of the most reliable for the evaluation of human motion, replicable in different fields and phases of development.

The reiterated practice of basic gymnastics movements in the intervention, such as rolls, multidirectional displacements, handstands, planks, twists, and jumps improve static balance while standing on two feet as well as on one foot; the latter without visual reference stands out. These gymnastics activities allow for the development of kinaesthetic awareness and spatial orientation.

It is determined that the ages of 14 to 17 years, those of the participants in this study, show higher imbalances for the craniocaudal and anteroposterior axes and, conversely, it shows that the medial-lateral axis presented less peaks and variations of movement, being the most stable axis.

The implementation of emerging methodologies in the study of human motion allows for more clarity and objectivity in research, giving way to the integration of deductive and inductive logic, and acknowledging that they can be of great scientific value.

\section{REFERENCES}

Abyarjoo, F., Barreto, A., Cofino, J., \& Ortega, F. R. (2014). Implementing a Sensor Fusion Algorithm for 3D Orientation Detection with Inertial/Magnetic Sensors. Innovations and Advances in Computing, Informatics, Systems Sciences, Networking and Engineering. Lecture Notes in Electrical Engineering, 313, 305-310. https://doi.org/10.1007/978-3-319-06773-5 41

Callejas-Cuervo, M., Alvarez, J. C. and Alvarez, D. (2016) Capture and analysis of biomechanical signals with inertial and magnetic sensors as support in physical rehabilitation processes. 13th International Conference on Wearable and Implantable Body Sensor Networks, San Francisco, CA. 119-123. https://doi.org/10.1109/bsn.2016.7516244

Callejas-Cuervo, M., M. Gutierrez, R., \& I. Hernandez, A. (2017). Joint amplitude MEMS based measurement platform for low cost and high accessibility telerehabilitation: Elbow case study. Journal of Bodywork \& Movement Therapies, 21, 574-581. https://doi.org/10.1016/j.jbmt.2016.08.016

Callejas-Cuervo, M., Ruíz-Olaya, A.F. and Gutiérrez, R.M. (2016). Validation of an inertial sensor-based platform to acquire kinematic information for human joint angle estimation. DYNA 83(197), 54-159.

Caña Pino, A., Apolo Arenas, M. D., Moral Blanco, J., Álvaro de Diego, J., \& Fernández Gutiérrez, C. (2015). Valoración del equilibrio postural en bipedestación-sedestación en sujetos sanos mediante acelerometría. Fisioterapia, 37, 271-278. https://doi.org/10.1016/..ft.2014.12.004 
Castañer Balcells, M., Camerino foguet, O., \& Anguera Argilaga, T. (2013). Métodos mixtos en la investigación de las ciencias de la actividad física y el deporte. Apunts. Educación Física y Deportes, 112, 31-36. https://doi.org/10.5672/apunts.2014-0983.es.(2013/2).112.01

Chia-Hsuan, L. \& Tien-Lung, S. (2018). Evaluation of postural stability based on a force plate and inertial sensor during static balance measurements. Journal of Physiological Anthropologi, 37, 27-37. https://doi.org/10.1186/s40101-018-0187-5

Contreras, R. (2011). La coordinación y el equilibrio dentro de la educación física actual. Efdeportes.com, 16(158), $1-5$.

Forechi, L., Nunes, G. S., Barbosa, M., Guerrieri Barbosa, E., Leite dos Santos, D., Ramos Vieira, E., \& Carvalho Barbosa, A. (2018). Pain, balance, grip strength and gait parameters of older adults with and without post-chikungunya chronic arthralgia. Tropical Medicine and International Healt, 23(12), 1394 - 1400. https://doi.org/10.1111/tmi.13154

Guimaraes Ribeiro, D., Hernández Suárez, M., Rodríguez Ruiz, D., \& García Manso, J. M. (2015). Efecto del entrenamiento sistemático de gimnasia rítmica sobre el control postural de niñas adolescentes. Revista Andaluza de Medicina del Deporte, 8, 54-60. https://doi.org/10.1016/i.ramd.2014.11.001

Leirós Rodríguez, R., Arce Fariña, E., \& García Soidán, J. L. (2015a). Estudio piloto para la valoración del equilibrio en mujeres adultas con un elemento cinemático. Retos 28, 90-93.

Leirós Rodríguez, R., Arce, E., García Soidán, J. L., \& Barbeito, G. (2017). Accelerometers: devices that contribute to healthy aging. Retos, 32, 44-47.

Leirós Rodríguez, R., Arce, M. E., Souto Gestal, A., \& García Soidán, J. L. (2015b). Identificación de puntos de referencia anatómicos para la valoración del equilibrio mediante dispositivos cinemáticos. Fisioterapia, 37, 223-229. https://doi.org/10.1016/i.ft.2014.10.006

Martínez Martínez, J., Contreras Jordán, O. R., Aznar Laín, S., \& Lera Navarro, Á. (2012). Niveles de actividad física medido con acelerómetro en alumnos de $3^{\circ}$ ciclo de Educación Primaria: actividad física diaria y sesiones de Educación Física. Psicología del Deporte, 21, 117-123. https://doi.org/10.24310/riccafd.2020.v9i2.7155

Medina Rivilla, A., De La Herrán Cascón, A., \& Domínguez Garrido, M. (2014). Fronteras en la investigación de la didáctica. Madrid: UNED.

Miralles; R. Vecchio; I. Ghersi, R. Paterson; F. Álvarez; M. P. Akly; Mariela Ferrando; A Paterson; Estudios de equilibrio en pacientes con riesgo de caída a partir de datos de acelerometría en tres ejes. Actas de las XIV Jornadas de Ingeniería Clínica y Tecnología Médica, 14, 1-5.

Morrisa, R., Douglas, N. M., Smulders, B. K., Kellyc, V., Zabetiand, C., Postonf, K., . . FayHoraka, J. (2019). Cognitive associations with comprehensive gait and static balance measures in Parkinson's disease. Parkinsonism \& Related Disorders, 60, 104-110.

Noamani, A., Nazarahari , M., Lewicke, J., Vettea, A., \& Rouhani, H. (2020). Validity of using wearable inertial sensors for assessing the dynamics of standing balance. Medical Engineering and Physics, 77, 53-59. https://doi.org/10.1016/i.medengphy.2019.10.018

Pacanchique Flórez, V. M. (2017). Análisis cinemático del ciclo de palada en kayakistas Boyacenses por medio de sensores de movimiento (Master's Thesis). Universidad Pedagógica y Tecnológica de Colombia, Tunja, Boyacá, Colombia.

Patel, M., Pavic, A., \& Goodwi, V. (2020). Wearable inertial sensors to measure gait and posture characteristic differences in older adult fallers and non-fallers: A scoping review. Graint \& posture, 76, 1101 - 1121. https://doi.org/10.1016/i.gaitpost.2019.10.039

Pineda Rojas, J. A. (2016). Análisis de a velocidad en la interceptación del balon en porteros de futból de salón con plataforma de captura de movimiento IMOCAP (Master's Thesis). Universidad Pedagógica y tecnológica de Colombia, Tunja, Boyacá, Colombia.

Tixa, S. (2006). Atlas of Palpatory Anatomy. MASSON, Elsevier. 


\section{(c) $)(1) \Theta(9)$}

This work is licensed under a Attribution-NonCommercial-NoDerivatives 4.0 International (CC BY-NC-ND 4.0). 